\title{
Bazı Bitki Ekstraktlarının Börülce Tohum Böceği [Callosobruchus maculatus F. (Coleoptera: Chrysomelidae)] Erginlerine Etkileri
}

\author{
Hüseyin ÇETí ${ }^{1^{*}}$, Fatma Nur ELMA ${ }^{1}$ \\ ${ }^{1}$ Selçuk Üniversitesi Ziraat Fakültesi Bitki Koruma Bölümü, Konya \\ [ORCID: http://orcid.org/0000-0002-3252-0778 (H. ÇETiN), 0000-0003-0985-0338 (F.N. ELMA)] \\ "Sorumlu yazar: hcetin@selcuk.edu.tr
}

\begin{abstract}
Öz
Bu araştırma tarçın Cinnamomum cassia (Blume), defne Laurus nobilis L., karanfil Syzygium aromaticum (L.) ve biberiye Rosmarinus officinalis L. bitkilerinden elde edilen ekstraktların, Callosobruchus maculatus F. erginlerine karşı kontakt ve yumurta bırakmayı engelleme etkilerini tespit etmek için yapılmışıı. Denemeler ve stok kültür yetiştirmeleri Selçuk Üniversitesi Ziraat Fakültesi Entomoloji laboratuvarı ve $30^{\circ} \mathrm{C}$ sıcaklık, \% 60-70 orantılı nem ve karanlık ortamdaki iklim kabininde 3 tekerrürlü olarak yürütülmüştür. Insektisit etki çalışmaları, ekstraktların beş konsantrasyonu (\%0.625, 1.25, 2.50, 5,10 $\mathrm{w} / \mathrm{w})$, yumurta bırakmayı engelleme çalışmaları ise ekstraktların üç konsantrasyonu (\%0.625, \%1.25, $\% 2.50 \mathrm{w} / \mathrm{w}$ ) kullanılmıştır. Kontak etki çalışmalarında, ekstraktların artan konsantrasyonları, 24 saat sonunda ölüm oranlarının artışına sebep olmuştur. Laurus nobilis $L$.'in $L C_{50}$ ve $L_{90}$ değerleri sırasıyla \% 2.02 ve \% 33.73; S. aromaticum'un ise \% 3.78 ve \% 37.20 olduğu tespit edilmiştir. Cinnamomum cassia ve $R$. officinalis ekstraktlarının kontakt toksisitesi oldukça düşük bulunmuştur. Yumurta bırakmayı engelleme etkisinin tespitinde püskürtme kulesi kullanılarak nohut daneleri üzerine $2 \mathrm{ml}$ ekstrakt püskürtülmüş, kurutulan danelerin bulunduğu petriye yeni çıkan bir çift ergin bırakılmıştır. Konsantrasyon artışına bağlı olarak yumurta bırakmayı engelleme oranı artmıştır. Bitki ekstraktlarının yumurta bırakmayı engelleme oranı \%2.50 konsantrasyonda en yüksek C. cassia (\% 43)'da, en düşük $R$. officinalis (\% 25)'te görülmüştür.
\end{abstract}

Anahtar Kelimeler: Callosobruchus maculatus, Bitki ekstraktları, Kontakt etki, Yumurta bırakmayı engelleme etkisi

\section{Effects of some plant extracts on adults of Cowpea weevil [Callosobruchus maculatus F. (Coleoptera: Chrysomelidae)]}

\begin{abstract}
This study was conducted to determine the contact and anti oviposition effects of cinnamon Cinnamomum cassia (Blume), laurel Laurus nobilis L., clove Syzygium aromaticum (L.) and rosemary Rosmarinus officinalis L. extracts against Callosobruchus maculatus F. adults. The experiments were conducted at Selcuk University, Faculty of Agriculture Entomology laboratory and climate chamber with the temperature of $30^{\circ} \mathrm{C}$ and $60-70 \%$ rate. The experiments were replicated for three times. Effects of the plant extracts were examined at five different concentrations $(0.625,1.25,2.50,5,10 \% \mathrm{w} / \mathrm{w})$ for contact toxicity and at three concentrations $(0.625,1.25,2.50 \% \mathrm{w} / \mathrm{w})$ for anti oviposition effect. In the contact effect study, the increasing concentrations of the extracts produced an increase in mortality rates after 24 hours. $\mathrm{LC}_{50}$ and $\mathrm{LC}_{90}$ values were determinated for $\mathrm{L}$. nobilis and S. aromaticum as $2.02 \%$ and $33.73 \%$ and $3.78 \%$ and $37.20 \%$, respectively. Contact toxicities of $C$. cassia and $R$. officinalis extracts were low. Anti oviposition (oviposition deterrent effect) effects of the plant extracts were determined by spraying of $2 \mathrm{ml}$ extract solution onto chickpea pods from spray tower and the seeds were dried and one pair of newly emerged adult $C$. maculatus were placed in each petri dish. Anti oviposition rates
\end{abstract}


increased with increasing concentrations. Maximum and minimum anti oviposition effect ratios at $2.50 \%$ extract concentration were observed in C. cassia and $R$. officinalis as $43 \%$ and $25 \%$, respectively.

Key Words: Callosobruchus maculatus, Plant extracts, Contact effect, Anti oviposition effect

\section{Giriş}

Baklagiller, günlük ihtiyaç duyulan hayvansal protein tüketiminin düşük olduğu gelişmekte olan ülkelerde insan beslenmesindeki en ucuz protein kaynağını oluşturmaktadır (Adedire, 2011). Türkiye'de yemeklik tane baklagiller insan beslenmesinde önemli bir yer tutmakta ve bitkisel protein ihtiyacının \% 18.5'ini baklagiller karşılamaktadır (Tamer, 1996).

Baklagiller depoda bulunduğu sürede özellikle böcekler tarafından ileri derecede zarara uğratılmaktadır. Callosobruchus maculatus, depolanmış baklagillerin en önemli zararlılarından biri olup, Türkiye'nin hemen her bölgesinde görülmekte ve hem üreticiler hem de toptancılar tarafından şikayetlere neden olmaktadır (Tamer, 1996).

Ağırlık kaybı, pazar değerinde düşme (Javaid ve Paswal, 1995; Elhag, 2000), tohumda çimlenme gücünün düşmesi ve protein içeriğinde azalma (Baier ve Webster, 1992) C. maculatus'un başlıca zararlarındandır. Tarlada zararlı ile sadece \% 1-2'lik bir bulaşmanın altı aylık depolama sonunda \%80'lik zarara sebep olduğu bildirilmiştir (Youdeowei, 1989). Hem tarlada, hem depoda bulaşmanın olabilmesi ve üreme gücünün yüksek olması bu zararlı ile mücadelenin oranında repellent etkiye sahip olduğu bildirilmiştir (Sagheer ve ark., 2014). Bitki ekstraktlarının depo zararlıları dışındaki önemini ortaya koymaktadır. Depo zararlılarının mücadelesinde organik, inorganik ve sentetik insektisitler yıllardan beri yaygın olarak kullanılmıştır. Ancak depolanmış baklagillerdeki kimyasal kalıntıların tüketicilerde kaygı oluşturması, böceklerde insektisitlere karşı direnç oluşması ve doğal dengenin olumsuz etkilenmesi mücadelede yeni arayışların ortaya çıkmasına neden olmuştur (Fields, 2006; Mahdi ve Rahman, 2008). Bitkisel kökenli insektisitler, özellikle de bitki ekstraktlarının depo zararlılarıyla mücadelede kullanılmasına yönelik yoğun çalışmalar yapılmıştır.

Thevetia peruviana Schum. kök ekstraktı C. maculatus erginlerine yüksek oranda toksik etki göstermiş (Mollah ve Islam, 2007); Prosopis juliflora' nın \% 1'lik konsantrasyonu C. maculatus'da \%52.5 oranında yumurta koymayı engellemiştir (Sathyaseelan ve ark., 2008). Artemisia vulgaris $L$. ve Tanacetum vulgare 'nin genç yapraklarından elde edilen ekstraktlar Sitophilus granarius ve Sitophilus oryzae üzerinde repellent etki göstermiştir (Ignatowicz, 1998). Trachyspermum ammi ve Syzygium aromaticum ekstraktlarının, Tribolium castaneum'da sırasıyla $\% 76.67$ ve $\% 76.54$ zararlılara karşı da etkinlikleri araştırılmıştır. Azadirachta indica'nın \% 2' lik çözeltisinin patates yapraklarına 
püskürtülmesinden sonra Leptinotarsa decemlineata larvaları beslenememiş (Kaethner, 1992); Melia volkensii Sieb. ekstraktı, Schistocerca gregaria Forsk. nimflerinde nimf dönemi süresini 2 kat uzatmıştır (Nasseh ve ark., 1993).

Bitki ekstraktları, beslenme engelleyici, büyüme düzenleyici ve uzaklaştıııcı etkileri yanında zararlılarda toksik ve yumurta bırakmayı engelleyici etkilerinden dolayı depo zararlılarının kontrolünde önemli bir yere sahiptir.

$\mathrm{Bu}$ çalışmada, dört farklı bitki ekstraktının C. maculatus'un erginlerine karşı kontakt toksisiteleri ve yumurta koymayı engelleme etkileri araştırılmıştır.

\section{Materyal ve Metot}

Araştırmada, dört bitkinin değişik kısımlarından (Çizelge 1) elde edilen ekstraktların biyolojik etkileri börülce tohum böceğinde test edilmiştir.

Kullanılan bitkiler ve ekstraktların elde edilmesi

Bitkilerden biberiye, Selçuk Üniversitesi Ziraat Fakültesi Tarla Bitkileri Bölümü'nün deneme tarlasında yetiştirilmiştir. Biberiyenin hasatı 12 Temmuz 2010'da yapraklı dönemde toprak yüzeyinden tüm bitki şeklinde biçilerek yapılmış, Tıbbi ve Aromatik Bitkiler Laboratuvarı'ndaki masalarda gölge ve havadar ortamda 6-7 gün kurutulmuştur. Tarçın, defne ve karanfil, tıbbi ve aromatik bitkiler marketinden alınmış, tür teşhisi Selçuk Üniversitesi Fen Fakültesi Biyoloji Bölümü'nden Doç. Dr. Evren Yıldıztugay tarafından yapılmıştır. Kullanılan bitkiler ve ekstrakt elde edilen kısımları Çizelge 1'de verilmiştir.

Kuru bitki örnekleri değirmen (Retsch SM100) yardımıyla öğütülmüş, 50'şer gr tartılıp üzerine $500 \mathrm{ml}$ methanol (Merck \% 99.5) eklenmiştir. Karışımlar cam kavanozlara aktarılmış, daha sonra ağız kısmı alüminyum folyo ile kapatılarak oda sıcaklığında 7-8 gün karanlık bir ortama koyulmuştur. Bu sürenin sonunda bitki süspansiyonları filtre (Whatman Filter Paper No:1) kağıdından süzülerek sıvı kısmı alınmış, Rotary Evaporatör (Heidolp-VAP Precision) yardımıyla 42 ${ }^{\circ} \mathrm{C}$ 'de düşük basınçta methanol uçurulmuştur. Elde edilen saf bitki ekstraktları methanol ile seyreltilip farklı konsantrasyonlarda (w/w) çözeltiler hazırlanmışır.

Callosobruchus maculatus kültürünün yetiştirilmesi

Yirmi çift bir iki günlük $C$. maculatus ergini, içerisinde $200 \mathrm{gr}$ nohut bulunan cam kavanozlara yerleştirilmiş ve ağız kısmı tülbentle kapatılmışır. Bu erginler, çiftleşip yumurta bırakmaları için 7 gün boyunca kavanozlar içerisinde bekletilmiştir. Daha sonra kavanozlardaki nohutlar elenmek suretiyle ergin bireyler ortamdan uzaklaştırımış, üzerinde yumurta olan nohut ergin bireyler çıkıncaya kadar kavanozlarda bekletilmiştir. Ergin çıkışı başlayan kavanozlardaki nohut 24 saat aralıklarla elenerek bir günlük ergin bireyler çalışmada kullanılmıştır. 
Çizelge 1. Ekstraktların elde edildiği bitkiler ve kısımları

Table 1. Plant species and parts of the plants used in making extracts

\begin{tabular}{|c|c|c|c|}
\hline $\begin{array}{l}\text { Familya } \\
\text { Family }\end{array}$ & $\begin{array}{l}\text { Latince adı } \\
\text { Scientific name }\end{array}$ & $\begin{array}{l}\text { Türkçe adı } \\
\text { English name }\end{array}$ & $\begin{array}{l}\text { Bitki kısmı } \\
\text { Plant parts }\end{array}$ \\
\hline Lauraceae & Cinnamomum cassia (Blume) & $\begin{array}{l}\text { Tarçın } \\
\text { Cinnamon }\end{array}$ & $\begin{array}{l}\text { Kabuk } \\
\text { Bark }\end{array}$ \\
\hline Lauraceae & Laurus nobilis L. & $\begin{array}{l}\text { Defne } \\
\text { Daphne }\end{array}$ & $\begin{array}{l}\text { Yaprak } \\
\text { Leaf }\end{array}$ \\
\hline Myrtaceae & Syzygium aromaticum (L.) & $\begin{array}{l}\text { Karanfil } \\
\text { Clove }\end{array}$ & $\begin{array}{l}\text { Çiçek tomurcuğu } \\
\text { Flower bud }\end{array}$ \\
\hline Lamiaceae & Rosmarinus officinalis L. & $\begin{array}{l}\text { Biberiye } \\
\text { Rosemary }\end{array}$ & $\begin{array}{l}\text { Yaprak, sap, gövde } \\
\text { Leaf, stalk, stem }\end{array}$ \\
\hline
\end{tabular}

Kontakt Etki çalışmaları

Her bitki ekstraktından methanol kulanılarak 5 konsantrasyonda çözeltiler (\% 0.625, 1.25, 2.50, 5, 10 w/w) hazırlanmıştır.

Farklı konsantrasyonlardaki çözeltiler mikropipet (Eppendorf 0.1-2.5 $\mu \mathrm{\mu l}$ ) yardımıyla, ergin dorsaline $2 \mu \mathrm{l} /$ ergin böcek olacak şekide damlatılmıştır. Damlatma uygulamasından önce erginler $2^{\circ} \mathrm{C}$ de 5 dakika tutularak hareketsiz kalmaları sağlanmış, kurutma kağıdı üzerinde damlatma uygulamasından sonra petri kabına alınmıştır. Damlatma uygulamasında damlacık hacminin değişmemesi için mikropipet ucu her üç veya dört damlatmada bir değiştirilmiştir. Denemeler tesadüf parsellerinde üç tekerrürlü olarak yürütülmüş ve her tekerrür için bir petri kabında 20 adet bir günlük ergin böcekler kullanılmıştır. Kontrollerde sadece methanol kullanılmıştır. 24 saat sonunda ölüler ince uçlu fırça ile dokunularak sayılmıştır. Denemeler ve stok kültür yetiştirmeleri $30^{\circ} \mathrm{C}$ sıcaklık, \% 60-70 orantılı nem ve karanlık ortamdaki iklim kabininde yürütülmüştür.
Yumurta koymayı engelleme etki çalışmaları

Yumurta koymayı engelleme testlerinde üç farklı konsantrasyonda (\% $0.625,1.25,2.50 \mathrm{w} / \mathrm{w}$ ) ekstrakt çözeltisi hazırlanmış, her bir petri kabına 10 adet nohut yerleştirilmiş ve daha sonra püskürtme kulesi (Manual Potter Spray Tower-Burkard Scientific Limited, Uxbridge, UK) kullanılarak $2 \mathrm{ml}$ ekstrakt 0.8 bar basınçla petri kaplarına püskürtülmüştür. Uygulamadan 1 saat sonra her petri kabındaki daneler temiz petri kaplarına aktarılmış ve her birine bir çift bir günlük ergin bırakılmıştır. Nohutlarda bulunan yumurtalar 15 gün sonunda sayılmıştır. Zararlının dane üzerine yapıştırarak bıraktığı yumurtaların sayımı stereo zoom mikroskop kullanılarak yapılmıştır. Üzerinde yumurta bulunan daneler ince uçlu pens yardımıyla tutularak ve orta çizgisi esas alınarak önce bir yarısı, sonra diğer yarısındaki yumurtalar sayılmıştır. Elde edilen sonuçların değerlendirilmesi

Kontakt etki testleri tesadüf parsellerinde üç tekerrürlü olarak yürütülmüş ve her tekerrür için bir petri kabında 20 adet bir günlük ergin böcekler 
kullanılmıştır. Abbott formülü ([(A-B)/A] $x$ 100; A, kontroldeki \% canlı; B, muameledeki \% canlı) ile düzeltilmiş ölüm oranları (\%) belirlenmiştir. Probit paket programı (LeOra, 1987) yardımıyla $L C_{50}$ ve $L C_{90}$ değerleri tespit edilmiştir.

Yumurta koymayı engelleme denemeleri tesadüf parsellerinde üç tekerrürlü olarak yürütülmüş ve içerisinde 10 adet nohut ile bir çift ergin bulunan petri bir tekerrürü oluşturmuştur. Ekstraktların yumurta koymayı engelleme oranları Y.K.E.O $(\%)=($ Kontroldeki Y. S.- Muameledeki Y.S./ Kontroldeki Y.S.)×100 formülü kullanılarak belirlenmiştir (Vanmathi ve ark., 2010).

\section{Araştırma Bulguları ve Tartışma}

Bitki ekstraktlarının C. maculatus erginlerinde 24 saatteki kontakt etkisi incelendiğinde; konsantrasyon artışına paralel olarak ergin ölüm oranlarında artış görülmüştür. Araştırmada kullanılan en yüksek ekstrakt konsantrasyonunda (\%10) S. aromaticum (L.) \% 80; L. nobilis L. \% 75; C. cassia (Blume) \% 54 ve $R$. officinalis L. \% 25 ergin ölümüne neden olmuştur. $\quad \mathrm{LC}_{50}$ ve $\mathrm{LC}_{90}$ değerleri incelendiğinde; $L$. nobilis ekstraktının düşük (\% 2.02; 33.73), S. aromaticum ekstraktının yüksek (\% 3.78; 37.20) olduğu tespit edilmiştir. C. cassia ve $R$. officinalis ekstraktlarının $\mathrm{LC}_{50}$ ve $\mathrm{LC}_{90}$ değerleri çok yüksektir (Çizelge 2.). LC 50 ve $\mathrm{LC}_{90}$ değerlerine göre, kontakt etkisi yüksek olan bitkiler $L$. nobilis ve $S$. aromaticum'dur. C. cassia ve $R$. officinalis ekstraktlarının kontakt etkisi oldukça düşük bulunmuştur. Mahdi ve Rahman
(2008), S. aromaticum'un $25 \mathrm{gr} / \mathrm{kg}$ ve 30 gr/kg dozlarındaki kuru tozunu Phaseolus bengalensis L. tohumlarıyla karıştırmışlar ve sonuçta $C$. maculatus erginlerinde sırasıyla 2.67 ve 2.0 günde $\% 100$ ölüm tespit etmişlerdir. Bhaduri ve ark., (1985), bankalmi (Persicaria hydropiper (L.)) bitkisinin yapraklarından elde edilen ekstraktların C. maculatus erginlerinde konsantrasyon artışına bağlı olarak yüksek kontakt etki gösterdiğini bildirmişlerdir. Kaju çekirdeğinin nhekzan, petrol eteri ve aseton ekstraktları, üç ay boyunca börülcede $C$. maculatus bulaşması ve zararını tamamen önlemiş, ekstrakt uygulanan danelerde ağılık kaybı ve zarar oluşmadığı görülmüştür (Adedire ve ark., 2011). Aynı araştırıcılar kaju çekirdeğinin C. maculatus üzerindeki insektisidal etkilerini belirlemek amacıyla farklı polaritede çözücüler kullanarak (hekzan, petrol eteri ve aseton) ekstraktlar elde etmişlerdir. Bu araştırıcılar yürütmüş oldukları çalışmada, $0.1 \mathrm{ml} / 20 \mathrm{gr}$ börülce danesi dozunda 96 saat sonunda hekzan, petrol eteri ve aseton ekstraktlarının sırasıyla \% 100, \% 96 ve \%98 gibi yüksek oranlarda ergin ölümüne neden olduğunu tespit etmişlerdir. Karakaş (2017), Anthriscus cerefolium, Laurus nobilis, Salvia officinalis, Foeniculum vulgare ve Rosmarinus officinalis bitkilerinden elde ettiği ekstraktların Sitophilus granarius' a etkisini araştırmış ve $R$. officinalis ekstraktının \%60.5 ölüm oranı ile ilk sırada yer aldığını, L. nobilis'in ise \%19.2 ile son sırada yer aldığını bildirmiştir. 
Çizelge 2. Farklı bitki ekstraktlarının değişik konsantrasyonlarının Callosobruchus maculatus erginlerinde 24 saatte meydana getirdiği ölüm oranları

Table 2. Mortality ratios in Callosobruchus maculatus adults of different concentrations of different plant extracts in 24 hours

\begin{tabular}{|c|c|c|c|c|}
\hline \multirow[b]{3}{*}{$\begin{array}{c}\text { Konsantrasyonlar (\%) } \\
\text { Concentrations (\%) }\end{array}$} & \multicolumn{4}{|c|}{$\begin{array}{c}\text { Ergin ölüm oranı (\%)* } \\
\text { Adult Mortality Rate (\%) }\end{array}$} \\
\hline & \multicolumn{4}{|c|}{$\begin{array}{l}\text { Bitkiler } \\
\text { Plants } \\
\end{array}$} \\
\hline & $\begin{array}{l}\text { Cinnamomum } \\
\text { cassia }\end{array}$ & Laurus nobilis & $\begin{array}{c}\text { Syzygium } \\
\text { aromaticum }\end{array}$ & $\begin{array}{l}\text { Rosmarinus } \\
\text { officinalis }\end{array}$ \\
\hline 0.625 & $18.64 \pm 0.45$ & $25.42 \pm 0.65$ & $22.03 \pm 0.52$ & $1.69 \pm 0.13$ \\
\hline 1.25 & $16.94 \pm 0.13$ & $45.76 \pm 0.13$ & $27.12 \pm 0.56$ & $5.08 \pm 3.35$ \\
\hline 2.5 & $38.98 \pm 0.59$ & $50.85 \pm 0.13$ & $30.51 \pm 0.52$ & $6.78 \pm 0.01$ \\
\hline 5 & $47.46 \pm 0.56$ & $71.19 \pm 0.56$ & $50.85 \pm 0.65$ & $10.17 \pm 0.13$ \\
\hline 10 & $54.24 \pm 0.59$ & $74.58 \pm 0.45$ & $79.66 \pm 0.39$ & $25.42 \pm 0.34$ \\
\hline Kontrol (Control) & $1.67 \pm 0.13$ & $1.67 \pm 0.13$ & $1.67 \pm 0.13$ & $1.67 \pm 0.13$ \\
\hline $\mathrm{LC}_{50}(\%)$ & $* *$ & 2.016 & 3.783 & $* *$ \\
\hline $\begin{array}{l}\text { Güven Aralığı } 0,95 \\
\text { Confidence Interval } \\
(0,95)\end{array}$ & - & $\begin{array}{l}1.240 \\
3.010\end{array}$ & $\begin{array}{l}2.447 \\
6.438\end{array}$ & - \\
\hline $\mathrm{LC}_{90}(\%)$ & - & 33.734 & 37.203 & - \\
\hline $\begin{array}{l}\text { Güven Aralığı } 0,95 \\
\text { Confidence Interval } \\
(0,95)\end{array}$ & - & $\begin{array}{c}14.928 \\
205.655\end{array}$ & $\begin{array}{c}16.155 \\
269.874\end{array}$ & - \\
\hline Eğim (Slope) & - & $1.047 \pm 0.185$ & $1.291 \pm 0.203$ & - \\
\hline$x^{2}$ & - & 14.299 & 21.040 & - \\
\hline
\end{tabular}

Ekstraktların konsantrasyon artışına bağı olarak yumurta bırakmayı engelleme oranı artmıştır. Bitki ekstraktlarının yumurta bırakmayı engelleme oranı \%2.50 konsantrasyonda en yüksek $C$. cassia (\%43)'da, en düşük $R$. officinalis (\%25)'te olmuştur (Çizelge 3 ). C. cassia ve $L$. nobilis ekstraktlarının yumurta bırakmayı engelleme etkisinin diğer iki bitki ekstraktından daha yüksek olduğu tespit edilmiştir. Sathyaseelan ve ark., (2008) Prosophis juliflora'nın \%1'lik yaprak ekstraktının C. maculatus'ta yumurta koymayı \%53 oranında engellediğini bildirmiştir. Adedire ve ark. (2011), Kaju çekirdeğinin aseton ekstraktının $0.1 \mathrm{ml} / 20 \mathrm{gr}$ börülce danesi uygulamasından sonra bir çift yeni çıkan ergini bu daneler üzerine bırakmışlar ve kontrolde 28.00 yumurta bırakan ergin aseton ekstraktında 10.50 adet yumurta bıraktığını bildirmişlerdir. Şenel (2013) yaptığı çalışmada $L$. nobilis ve $R$. officinalis ekstraktlarının T. absoluta'nın yumurta bırakmasını engelleyici etkilerinin oldukça yüksek olduğu ve \% 100' e varan düzeylere ulaşabildiğini rapor etmiştir. 
Çizelge 3. Farklı bitki ekstraktlarının Callosobruchus maculatus dişilerinde yumurta bırakmayı engelleme etkileri

Table 3. Effects of different plant extracts on laying of Callosobruchus maculatus females

\begin{tabular}{lccc}
\hline \multicolumn{4}{c}{$\begin{array}{c}\text { Yumurta bırakmayı engelleme oranı (\%)* } \\
\text { Oviposition Deterrent rate (\%) }\end{array}$} \\
\hline \multicolumn{3}{c}{$\begin{array}{c}\text { Konsantrasyonlar (\%) } \\
\text { Concentrations (\%) }\end{array}$} \\
\cline { 2 - 4 } Bitkiler & 0.625 & 1.25 & 2.5 \\
Plants & $29.47 \pm 2.12$ & $35.79 \pm 0.10$ & $43.16 \pm 0.83$ \\
\hline Cinnamomum cassia (Blume) & $8.42 \pm 2.19$ & $40.00 \pm 1.06$ & $42.63 \pm 2.32$ \\
Laurus nobilis L. & $19.47 \pm 0.37$ & $24.21 \pm 0.72$ & $36.84 \pm 0.63$ \\
Syzygium aromaticum (L.) & $18.42 \pm 1.12$ & $21.58 \pm 0.57$ & $25.26 \pm 0.59$ \\
Rosmarinus officinalis L. & \multicolumn{3}{c}{. }
\end{tabular}

* Ortalama \pm St. Hata (Average $\pm S E$ )

\section{Sonuçlar}

Araştırmamızda $L$. nobilis ve $S$. aromaticum ekstraktlarının zararlı erginlerine kontakt toksisitelerinin, $C$. cassia ve $L$. nobilis ekstraktlarının ise yumurta bırakmayı engelleme etkisinin yüksek olduğu tespit edilmiştir. L. nobilis ve $S$. aromaticum ekstraktlarının biyopestisit olma potansiyelleri olduğundan zararlı böcek türleri ve onların farklı biyolojik dönemlerine toksik etkilerinin araştırılması bitki koruma, çevre ve insan sağığı açısından faydalı olacaktır. Ekstraktların zararlılarla mücadelede kullanılabilmesi için düşük konsantrasyonlarda etkili olan bitki türlerinin tespit edilmesi önemlidir. Bu yüzden çalışılmamış olan bitki türlerinden elde edilen ekstraktların zararlılara kontakt, rezidüel, repellent, beslenmeyi engelleyici, yumurta koymayı engelleyici ve zararlı gelişimini engelleyici gibi etkilerinin araştırılması son derece önemlidir. Ayrıca elde edilen ekstraktların diğer böcek türlerine ve hedef olmayan omurgasızlara karşı seçicilikleri ile moleküler biyolojik veya biyokimyasal teknikler kullanılarak etki mekanizması üzerinde çalışı Iması da yeni biyopestisitlerin geliştirilmesi açısından faydalı olacaktır (Kim ve ark., 2012).

\section{Ekler}

Bu çalışma 28-30 Haziran tarihinde Kahramanmaraş'ta düzenlenen Türkiye IV. Bitki koruma kongresinde poster olarak sunulmuş ve özet olarak basılmıştır.

\section{Kaynaklar}

Adedire, C. O., Obembe, R., Akinkurolere O., Oduleye S. O., 2011. Response of Callosobruchus maculatus (Coleoptera: Chrysomelidae: Bruchinae) to extracts of cashew kernels. Journal of Plant Diseases and Protection, 118 (2): 75-79.

Baier, H., Webster, B. D., 1992. Control of Acanthoscelides obtectus Say (Coleoptera: Bruchidae) in Phaseolus vulgaris L. seed stored on small farms- II. Germination and cooking time. Journal of Stored Product Research, 28: 295-298.

Bhaduri, N., Ram, S., Patil, B. D., 1985. Evaluation of some plant extract as protectants against pulse beetle, Callosobruchus maculatus F. infesting cowpea seeds. Journal of Entomological Research, 9 (2): 183-187. 
Elhag, E. A., 2000. Deterrent effect of some botanical products on oviposition of the cowpea bruchid Callosobruchus maculatus (F.) (Coleoptera:Bruchidae). International Journal of Pest Management, 46: 109-113.

Fields, P.G., 2006. Effect of Pisum sativum fractions on the mortality and progeny production of nine stored-grain beetles.

Javaid, I., Poswal, M .A. T., 1995. Evaluation of certain spices for the control of Callosobruchus maculatus (Coleoptera: Bruchidae) in cowpea seeds. African Entomology, 3: 87-89.

Kaethner, M., 1992. Fitness reduction and mortality effects of neem-based pesticides on the Colorado potato beetle Leptinotarsa decemlineata Say (Coleoptera: Chrysomelidae). Journal of Applied Entomology, 113: 456-465.

Karakaş, M., 2017. Use of aromatic plant extracts as bio-insecticides for the control of stored-product insect, Sitophilus granarius. International Journal of Entomology Research, 2(1): 27-29.

Kim, S., Ahn, Y., Kwon H., 2012. Toxicity of aromatic plants and their constituents against Coleopteran stored products insect pests. "Alınmıştır: New Perspectives in Plant Protection. (Ed) Bandani, A.R.,In Tech, Available from: http://www.intechopen.com/books/newp erspectives-in-plant-protection/toxicity-ofaromatic-plants-and-their-constituentsagainst-coleopteran stored productsinsect-pests.

LeOra Software, 1987. A User's guide to probit and logit analysis. LeOra Software, Berkeley, California.

Mahdi, S. H. A., Rahman, M. K., 2008. Insecticidal effect of some spices on Callosobruchus maculatus (Fabricius) in black gram seeds. University Journal of Zoology, 27: 47-50.

Mollah, J.U., Islam, W., 2007. Toxicity of Thevetia peruviana (Pers) Schum. extract to adults of Callosobruchus maculatus F. (Col.: Bruchidae). Journal of Agriculture Rural Development, 5(1): 105-109.

Nasseh, O., Wilps, H., Rembold, H., Krall, S., 1993. Biologically active compounds in Melia volkensii: larval growth inhibitor and
Journal of Stored Products Research, 42: 86-96.

Ignatowicz, S. ,1998. Powdered herbs of the daisy family (Compositae) as repellents or attractants for the grain weevil, Sitophilus granarius (L.), and the rice weevil, $S$. oryzae (L.). Annals of Warsaw Agricultural University SGGW, Horticulture (Landscape Architecture), 19: 15-28.

phase modulator against the deserty locust Schistocerca gregaria (Forskal) (Orth.: Crytacanthacrinae). Journal of Applied Entomology, 116: 1-11.

Sagheer, M., Hasan, M., Najam-ul-Hassan, M., Farhan, M., Ahmad Khan, F. Z., Abdul Rahman, 2014. Repellent effects of selected medicinal plant extracts against Rust-Red Flour Beetle, Tribolium castaneum (Herbst) (Coleoptera: Tenebrionidae). Journal of Entomology and Zoology Studies, 2 (3): 107-110.

Sathyaseelan, V., Baskaran, V., Mohan, S., 2008. Efficacy of some indigenous pesticidal plants against pulse beetle, Callosobruchus chinensis (L.) on green gramineae. Journal of Entomology, 5 (2): 128-132.

Şenel, M., 2013. Bazı bitkisel ekstraktların Tuta absoluta (Meyrick, 1917) (Lepidoptera: Gelechiidae)'nin farklı biyolojik dönemlerine etkisi. Doktora Tezi, Adnan Menderes Üniversitesi Fen Bilimleri Enstitüsü, Aydın, 53s.

Tamer, A., 1996. Acanthoscelides obtectus (Say) ve Callosobruchus maculatus F.'un gelişme süresi üzerine sıcaklığın ve besinin etkilerinin araştırılması. Türkiye 3. Entomoloji Kongresi Bildiri Özetleri, 24-28 Eylül, 200-205s. Ankara.

Vanmathi, J. S., Padmalatha, C., Sing A.J.A., Isaac, S.S., 2010. Efficacy of selected plant extracts on the oviposition deterrent and adult emergence activity of Callosobruchus maculatus F. (Bruchidae; Coleoptera). Global Journal of Science Frontier Research, 10 (8): 2-6.

Youdeowei, A., 1989. Major arthropod pest of food and industrial crops in Africa and their economic importance. Proceedings of the Inaugural Conference and Workshop of the IITA, 31-50 pp. Abidjan, Nigeria. 